\title{
Observation on the embryonic development of Varroa destructor Anderson and Trueman, 2000 (Mesostigmata-Varroidae)
}

\author{
A. M. Afifi; A. A. El-Sherif and Sally F.M. Allam \\ Dept. of Zoology and Agricultural Nematology, Fact. of Agric., Cairo Univ., Giza, Egypt
}

\begin{abstract}
The embryonic development of Varroa destructor Anderson and Trueman,2000 was investigated during the period from egg deposition until hatching to protonymphal stage. Formation of the gnathosoma and development of legs as well as the chaetotaxy and leg segmentation were followed up, described and illustrated during the development of Varroa embryo within the chorion.
\end{abstract}

Key Words: Acari,Varroidae, Varroa destructor, Embryonic development.

\section{INTRODUCTION}

Little is known about acarine embryogenesis (Walter, 2009). The embryonic development of the mesostigmatic mite; Hypoaspis aculeifer Canestrini was described and illustrated by Ignatowicz (1974). All ixodid and mesostimated eggs are similar in their basic structure, the germ band elongates and gives rise to the cephalic lobes, after which the prosomatic segments with limb buds become distinct (leg segments I - III,followed by pedipalps, legs IV and cheliceral segments). Legs IV do not progress but remain as buds as the other limbs begin to grow (Aeschlimann and Hess, 1984).

Kang-Chen and Rou-Su (1975) described one egg and three embryos of Varroa jacobsoni Oudemans. They reported that the egg was formed in the ovary and the embryo was developed until became a complete larva then deposited. DelfinadoBaker (1984) described and figured protonymph and deutonymph of V.jacobsoni for the first time.Mautz et al.(1986) demonstrated the different embryonic stages of $V$. jacobsoni and stated that, a mobile and free-living six- legged larva did not occur. No larval stage was recorded in Varroa life cycle as larva completed its development inside the egg shell before hatching (Ifantidis, 1983 and Afifi et al.,1998). Akimov and Yastrebtsov (1991) reported that the whole ontogeny from egg to formed protonymph in the chorion proceeds very intensively (26 to 30 hours).Balint et al. (2009) stated that the ontogenesis of $V$. destructor can be structured in embryonic development and postembryonic development.The post-embryonic development has four stages: larva, protonymph with a mobile phase and an immobile phase;deutonymph with the same two phases and adult. They added removal of pre-larval and tritonymphal stages in the biological cycle in order to reduce the development of Varroa mite.
The objectives of the present study are to throw more light on detailed morphological characterization of $V$. destructor embryo; to follow up the formation of gnathosoma; development of legs and their segmentation and chaetotaxy during the development of embryo within the chorion.

\section{MATERIALS AND METHODS}

Eggs of $V$. destructor were collected from recently sealed worker and drone brood cells of Apis mellifera in the apiary of the Agricultural Experimental Station, Faculty of Agriculture, Cairo University. Brood cells were examined after capping at successive 3 hours intervals. The eggs at different embryonic development were picked up from the brood cells by means of camel hair brush. Eggs were mounted on microscopic slides, using Hoyer's medium. Mounted eggs were examined, measured, drawn and illustrated.

\section{RESULTS AND DISCUSSION}

The incubation period of Varroa eggs averaged one day for both male and female in bee worker and drone brood cells. Egg hatching occurred giving directly rise to protonymph. No mobile larval stage was recorded, as larva completed its development inside the egg shell. The following figures illustrate the development of Varroa embryo within the chorion.

\section{-Egg of V. destructor: (Fig. 1)}

The newly laid egg is broadly oval, whitish translucent and measures $625 \mu$ long and $450 \mu$ wide. The egg shell and vesiculated yolk substances are clearly visible. Neither germination nor any step towards the development of an embryo are discernible.

\section{-Early six-legged embryo: (Fig. 2)}

The egg has subspherical shape, measures $620 \mu$ 



\section{Explanation of figures :}

Fig.(1): Egg of Varroa destructor.

Fig. (2): Early six-legged embryo.

Fig. (3): Six-legged embryo.

Fig. (4): Advanced six-legged embryo.

Fig. (5): Further Advanced six-legged embryo.
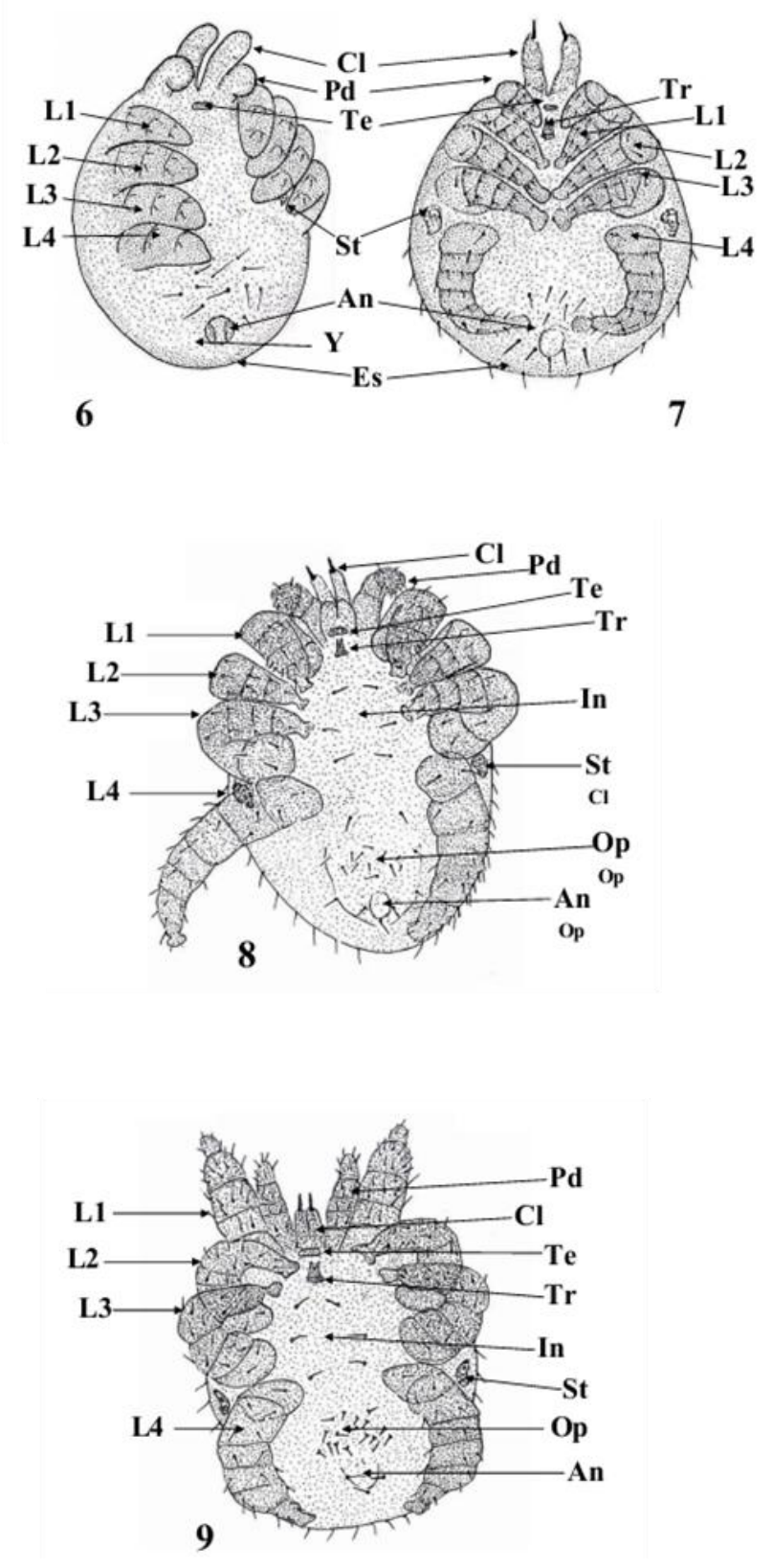

Fig. (6): Early eight-legged embryo.

Fig. (7): Eight-legged embryo.

Fig. (8): Developed eight-legged embryo.

Fig. (9): Fully developed eight-legged embryo.
Es: Egg shell;

Pd: Pedipallp;

St: Stigma;

Op: Opisthogastric region;
Yo: Yolk;

Te: Tectum;

Tr: Tritosternurn;

L1, L2, L3, L4: Leg I, II, III and IV.
Cl: Chelicera;

An: Anal shield;

In: Intercoxal region; 
long and $584 \mu$ wide. Six tenuous legs of the embryo are clearly visible at one end of the egg, the embryo seems to fill about $25 \%$ of the egg and the yolk substances $75 \%$. The rudiments of pedipalps and chelicerae are visible.

\section{-Six-legged embryo: (Fig. 3)}

The egg has subspherical shape, measures $660 \mu$ long and $570 \mu$ wide. The six legs are distinctly bulging the egg shell. The legs and palps are greater in their volume than those in Fig. (2). Legs are with three segments; while each of palp and chelicera with 2 segments. About one half of the egg is filled by the embryo.

\section{-Advanced six-legged embryo: (Fig. 4)}

The egg has an elliptical shape and measures $685 \mu$ long and $510 \mu$ wide. Legs, palps and chelicerae are greater in volume than those in Fig. (3), rudiment of tectum in the level of coxae I and about one half of the egg is filled with embryo. No setae are visible on legs.

\section{- Further advanced six-legged embryo: (Fig. 5)}

The egg has an elliptical shape, measures $670 \mu$ long and $570 \mu$ wide. Palps, chelicerae and six legs are distinctly bulging the egg shell, bent to venter and are greater in their volume than those in (Fig. 4). Legs with noticeable needle-like setae. Tectum appears between coxae I, and has a smooth anterior margin.

\section{-Early eight-legged embryo: (Fig. 6)}

The egg has an elliptical shape, measures $680 \mu$ long and $595 \mu$ wide. The primary development of protonymphal stage is visible within the egg, the four pairs of legs and palps are bent to ventral side of egg shell. Legs with noticeable acute, conical setae. Opisthogastric region with simple setae and the anal shield is visible. Rudiments of stigma and peritreme are located between coxae III and IV. Dorsal setae are acute, conical and with concave base.

\section{-Eight-legged embryo: (Fig. 7)}

Egg measures $695 \mu$ long and $545 \mu$ wide. The embryo within partially burst egg shell and tectum as in Fig. (6). Tritosternum is rudimentary, short and with two undeveloped laciniae. Chelicerae have the non-chelate form, as the fixed digit is completely lacking and movable digit is pointed. The four pairs of legs are with visible setae and their ambulacra lacking claws. Stigma present and the peritreme undeveloped. Dorsum and opisthogastric cuticle show marked hypotrichy. Marginal setae are visible and pointed.

\section{-Developed eight-legged embryo: (Fig. 8)}

It measures $684 \mu$ long and $475 \mu$ wide. Chelicerae are clearly visible, with only movable digit and palps have three segments. Legs I, II and III are bent against each other, setae of leg coxae are visible and ambulacrae of legs are lacking claws. Intercoxal region are with three pairs of setae. Anal shield has three setae. Opisthogastric cuticle with setae being concentrated of region above anal shield and lacking on area below coxae IV. Dorsum cuticle shows marked hypertrichy. Marginal setae as in Fig. (7).

\section{-Fully developed eight-legged embryo : (Fig. 9)}

Oval in shape, measures $695 \mu$ long and $535 \mu$ wide, palps and legs radially stretched off from the body. Chelicerae are visible, between palps. Chelicerae, legs, stigma, peritreme and anal shield are as in Fig. (8). The marginal setae of opisthosomal region are pointed and radially standing off. Dorsum surface and opisthogastric cuticle show marked hypertrichy.

Segmentation of legs, pedipalps and chelicerae is early started during the development of six-legged embryo. The chaetotaxy of legs and pedipalps as well as tectum are being visible at the late phase of six-legged embryo, and develop on the subsequent circumstances. On the other hand, tritosternum, stigma and peritreme are evident in the early eightlegged embryo and being visible in the eight-legged embryo. No dorsal or ventral setae appeared in sixlegged embryo but being visible in the eight-legged embryo. These setae are hypertrichy in the late phase of eight-legged embryo.

The larval stage develops inside the egg chorion and hatching occurs giving directly rise to protonymph .Some permanent vertebrate-parasitic Dermanyssoidea give birth to protonymphs skipping an active larva entirely (Radovsky, 1994).On the other hand, no prelarvae have been reported from the Parasitiformes (Walter and Proctor,1999). Varroa mite follows similar trend of mesostigmatid mites in post embryonic development, without prelarval or tritonymphal stage.

\section{REFERENCES}

Aeschlimann, A. and Hess, E.1984.What is our current knowledge of acarine embryology? in Griffiths and Bowman, Acarology, 6( 1): 90-99.

Afifi, A. M.; El-Shemy, A. A. M. and Allam, Sally. F.1998.Behviour, reproduction and life cycle of Varroa jacobsoni Oud. under Egyptian conditions. J. Agric. Sci., Mansoura Univ., 
23:419-429.

Akimov, I. A. and Yastrebtsov, V. A.1991. Peculiarities in ontogenesis and reproductive cycle of the mite Varroa jacobsoni (Parasitiformes, Varroidae) and its relation to the host Apis mellifera. Wiad Parazytol., 37(1): 99102.

Anderson, D. L. and Trueman, J. W. H. 2000.Varroa jacobsoni (Acari: Varroidae) is more than one species Apidologie, 14: 197-204.

Balint, A.;Cosorosbs,I. G. H.; Darabus,G. H; Ilie, M. S. and Mandita, D. N. (2009). Particular evolutionary phenomena in ontogenesis of Varroa destructor. Lucrari Stiiniifice Medicina Veterinara,32 (1): 89-93.

Delfinado-Baker, M. 1984.The nymphal stages and male of Varroa jacobsoni Oudemans, a parasite of honey bees. Inter. J. Acarol., 10: 75-80.

Ifantidis, M.D.1983. Ontogenesis of the mite Varroa jacobsoni in worker and drone honey bee brood cells. Journal of Apicultural Research, 22: 200 2006.

Ignatowicz, S.1974. Observation on the biology and development of Hypoaspis aculeifer Canestrini, 1885 (Acarina, Gamasides). Zoologica Poloniae, 24: 41-59.

Kang-Chen, L. and Rou-Su, C. 1975. The preliminary investigation on bee mites in Taiwan. J. Agric. Res. China, 24(12): 50-56.

Mautz, D.; Hirschmann, W. and Kemnitzer, F. 1986. The embryonic development of Varroa jacobsoni Oudemans, 1904 (Varroidae, Mesostigmata). Acarologia, 27: 203-210.

Radovsky, F. J. 1994.The evolution of parasitism and the distribution of some dermanosoid mites (Mesostigmata) on vertebrate hosts. In Mites, Ecological and Evolutionary Analysis of Life History Patterns, pp. 186-217. ed. M. A. Houck. Chapman \& Hall: New York.

Walter, D. E. 2009. Reproduction and Embryogenesis. In A Manual of Acarology, Krantz and Walter Third Ed. Texas Tech University Press : 54 -56.

Walter. D. E. and Proctor, H. C. 1999. Mites Ecology, Evolution and Behaviour. CABI publishing, $321 \mathrm{pp}$. 